Wright State University

CORE Scholar

Physics Faculty Publications

Physics

$11-1-2002$

\title{
Deep Electron and Hole Traps in Freestanding N-GaN Grown by Hydride Vapor Phase Epitaxy
}

\author{
A. Y. Polyakov \\ N. B. Smirnov \\ A. V. Govorkov \\ Z-Q. Fang \\ David C. Look \\ Wright State University - Main Campus, david.look@wright.edu
}

See next page for additional authors

Follow this and additional works at: https://corescholar.libraries.wright.edu/physics

Part of the Physics Commons

\section{Repository Citation}

Polyakov, A. Y., Smirnov, N. B., Govorkov, A. V., Fang, Z., Look, D. C., Park, S. S., \& Han, J. H. (2002). Deep Electron and Hole Traps in Freestanding N-GaN Grown by Hydride Vapor Phase Epitaxy. Journal of Applied Physics, 92 (9), 5241-5247. https://corescholar.libraries.wright.edu/physics/151

This Article is brought to you for free and open access by the Physics at CORE Scholar. It has been accepted for inclusion in Physics Faculty Publications by an authorized administrator of CORE Scholar. For more information, please contact library-corescholar@wright.edu. 


\section{Authors}

A. Y. Polyakov, N. B. Smirnov, A. V. Govorkov, Z-Q. Fang, David C. Look, Seong-Ju S. Park, and J. H. Han 


\title{
Deep electron and hole traps in freestanding $n$-GaN grown by hydride vapor phase epitaxy
}

\author{
A. Y. Polyakov, N. B. Smirnov, and A. V. Govorkov \\ Institute of Rare Metals, Moscow, 109017, B. Tolmachevbsky, 5, Russia
}

Z.-Q. Fang ${ }^{\text {a) }}$ and D. C. Look

Semiconductor Research Center, Wright State University, Dayton, Ohio 45435

S. S. Park and J. H. Han

Samsung Advanced Institute of Technology, P.O. Box 111, Suwon, Korea, 440-600

(Received 20 June 2002; accepted 2 August 2002)

\begin{abstract}
Deep level electron and hole traps were studied by means of deep level transient spectroscopy with electrical and optical injection on a freestanding thick $n$-GaN sample with low dislocation density. It is shown that at both the upper and the lower surface of the sample there exists a thin, $\sim 0.5 \mu \mathrm{m}$ layer of damaged material with lowered concentration of electrons and enhanced density of deep centers. Deep in the bulk of the film the densities of the majority of the electron and hole traps are shown to be very low, but measurably higher on the lower face $(\mathrm{N}$ face), which was originally closer to the $\mathrm{Al}_{2} \mathrm{O}_{3}$ substrate. The two faces are also shown to similarly differ in the density of deep hole traps whose concentration is deduced from low-temperature capacitance-voltage measurements in the dark and after illumination (such traps were previously associated with dislocation states). The concentration of persistent photocapacitance centers is shown to be very low on both sides and considerably lower than previously reported for other $n$-GaN samples with higher dislocation densities. Electron beam induced current measurements on both sides of the sample reveal the presence of dark spots whose density roughly correlates with the density of dislocations at the upper and lower faces. The reverse current at high voltages is shown to be considerably higher on the $\mathrm{N}$ face. The possible relationship of the observed phenomena to dislocations is discussed. (C) 2002 American Institute of Physics. [DOI: 10.1063/1.1511823]
\end{abstract}

\section{INTRODUCTION}

Freestanding thick GaN samples grown by hydride vapor phase epitaxy (HVPE) have recently drawn much attention as potential substrates for growth of high-quality $\mathrm{GaN}$ structures. ${ }^{1-3}$ The improvements of the quality of the material achieved during the last several years were truly remarkable and, for instance, Samsung Electronics, Inc. was able to demonstrate thick, freestanding GaN samples with a dislocation density at the upper $(\mathrm{Ga})$ surface as low as $10^{6} \mathrm{~cm}^{-2}$ and densities of residual donors and acceptors as low as 7 $\times 10^{15}$ and $2 \times 10^{15} \mathrm{~cm}^{-3}$, respectively. ${ }^{4,5}$ Studying such crystals is also very interesting from a purely scientific viewpoint because it provides access to reasonably low dislocation density material which makes it possible to separately study the impact of point defects and dislocations on the electrical and recombination properties of $n$-GaN. Preliminary measurements of electrical properties (e.g., Schottky barrier height),${ }^{6}$ deep level spectra, ${ }^{6}$ defect structure by transmission electron microscopy (TEM), ${ }^{4}$ and luminescence properties ${ }^{7}$ have shown the existence of interesting differences in characteristics of the upper, low-dislocation-density $\mathrm{Ga}$ side, and the lower, higher-dislocation-density $\mathrm{N}$ side. Moreover, they have revealed the presence of thin damaged layers at both surfaces caused by the sample preparation rou-

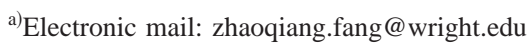

tines. In this work, we have studied in more detail the differences between the surface and bulk electron traps on both sides of the freestanding Samsung samples. We have also investigated the hole traps in such material by means of optical deep level transient spectroscopy (DLTS) and lowtemperature capacitance-voltage measurements. ${ }^{8}$ Furthermore, we have determined the densities of the persistent photocapacitance centers by measuring low-temperature $C-V$ before and after illumination, ${ }^{9}$ and have compared the electron beam induced current (EBIC) images of both sides of the sample to see if any features could be attributed to dislocations. Finally, we have compared the reverse current current-voltage $(I-V)$ characteristics to see if the difference in dislocation density has any impact on the level of reverse current. We also correlate the results of all these measurements with those obtained earlier on a set of HVPE grown $n$-GaN films on sapphire substrates with higher dislocation density.

\section{EXPERIMENT}

The freestanding sample of undoped $n$-GaN was grown by hydride vapor phase epitaxy at Samsung, as described, e.g., in Ref. 1, and was detached from its sapphire substrate. The overall thickness of this freestanding sample was initially about $500 \mu \mathrm{m}$. To flatten the wafer, approximately 50 $\mu \mathrm{m}$ of material was lapped from both the substrate side and the layer side, and then both sides were subjected to reactive 
ion etching (RIE) to improve the surface morphology. Detailed transmission electron microscope (TEM) studies have not been made on this particular sample but previous measurements on similarly grown freestanding samples found surface dislocation densities of mid- $10^{6} \mathrm{~cm}^{-2}$ on the upper side of the wafer and low- $10^{7} \mathrm{~cm}^{-2}$ on the lower side. We assume that these values are similar to those existing in the present sample. As discussed previously (see Ref. 6), the upper surface of the grown film was terminated by Ga atoms, and the substrate side, by $\mathrm{N}$ atoms. Hence, the upper and the lower sides of the films will hereafter be called the Ga side, and the $\mathrm{N}$ side, respectively, in harmony with current practice. All electrical measurements, on both the Ga and $\mathrm{N}$ sides, were performed on Au Schottky diodes $0.75 \mathrm{~mm}$ $\times 0.75 \mathrm{~mm}$ in area, prepared by vacuum evaporation through a shadow mask, as described in Ref. 10. The ohmic contact was an indium pad prepared on the same surface as the Schottky diode.

The measurements included capacitance-voltage data at frequencies from $100 \mathrm{~Hz}$ to $10 \mathrm{MHz}$ and at temperatures from 85 to $400 \mathrm{~K}$, with and without UV illumination from a deuterium lamp. We investigated deep electron trap spectra by applying the DLTS technique with electrical pulse injection, ${ }^{11}$ and studied deep hole trap spectra by using optical injection pulses. ${ }^{12}$ The densities of deep hole traps with levels located below the Fermi level were also measured from the change in the intercept value in low-temperature $C-V$ characteristics after illumination, as discussed in some detail in Refs. 8 and 13. The density of traps giving rise to persistent photocapacitance (PPC) was deduced from comparing the slopes of $C-V$ characteristics of the samples cooled in the dark before and after illumination as discussed, e.g., in Ref. 9. The uniformity of the deep traps was studied by measuring the spatial distribution of the electron beam induced current (EBIC) signal when imaging the sample in the scanning electron microscope (SEM). The values of diffusion length of minority carriers were deduced from the EBIC profiles obtained when scanning the probing electron beam of the SEM along the surface of the sample towards the Schottky diode as discussed in Ref. 14. All of these experimental techniques are fairly standard and more detailed descriptions of the experimental setups can be found, e.g., in Refs. 13-15.

\section{RESULTS AND DISCUSSION}

\section{A. Damaged layers at $\mathbf{G a}$ and $\mathbf{N}$ surfaces}

In Fig. 1 we present the $1 \mathrm{MHz} 1 / \mathrm{C}^{2}-V$ characteristics measured on both the $\mathrm{Ga}$ and $\mathrm{N}$ sides of the film. It can be seen that the slope for voltages below $-1 \mathrm{~V}$ is for both surfaces very measurably different from the slope for higher voltages which means that in the surface region about $0.5-$ $0.6 \mu \mathrm{m}$ deep (the thickness of the space charge region corresponding to $-1 \mathrm{~V}$ bias) the apparent electron concentration is substantially lower than in the bulk of the film. This phenomenon is most likely due to radiation damage introduced into the near-surface region by the reactive ion etching process.

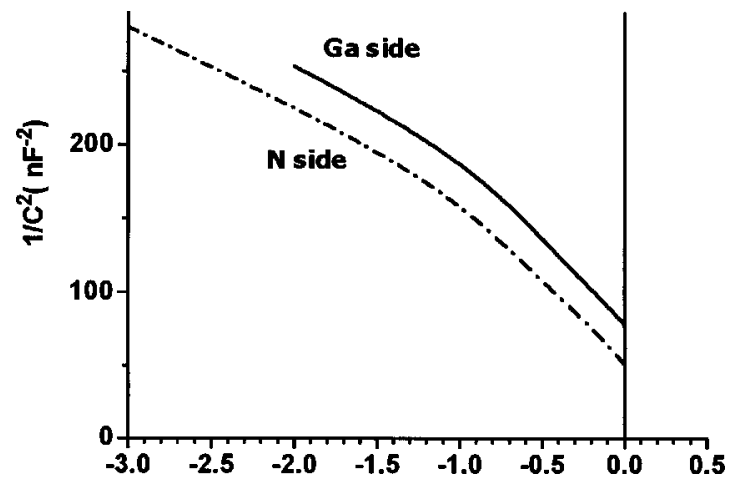

FIG. 1. The $1 \mathrm{MHz}, 290 \mathrm{~K} C-V$ characteristics measured on the Ga side (solid line) and the $\mathrm{N}$ side (dashed line) of the freestanding Samsung sample.

The room-temperature concentration profile obtained on the $\mathrm{N}$ side of the sample is shown in Fig. 2. The apparent electron concentrations at the surface and in the bulk, measured on the Ga side and on the $\mathrm{N}$ side, are presented in Table I (the data refer to $85 \mathrm{~K}$ but the temperature dependence of concentration in this sample was very slight). As can be seen, the electron concentration in the bulk of the film was slightly higher on the $\mathrm{N}$ side compared to that on the $\mathrm{Ga}$ side.

The near-surface region is also characterized by a much higher density of deep electron traps as becomes obvious from comparing the DLTS spectrum taken with reverse bias of $-0.8 \mathrm{~V}$ and forward bias pulse of $1 \mathrm{~V}$ (conditions that probe the damaged near-surface region) as opposed to the spectrum taken with reverse bias of $-3 \mathrm{~V}$ and forward bias pulse of $-1 \mathrm{~V}$ (conditions that probe the bulk of the film, according to $C-V$ results in Fig. 1. See Fig. 3 for the Ga side of the sample; the results for the $\mathrm{N}$ side are quite similar.) The traps most conspicuous in the near surface region are the $0.2 \mathrm{eV}$ (apparent concentration of $4.9 \times 10^{13} \mathrm{~cm}^{-3}$ ) and 0.32 $\mathrm{eV}\left(6 \times 10^{13} \mathrm{~cm}^{-3}\right)$ traps, previously shown to be related to point defects introduced by electron irradiation or during sputter deposition of Au Schottky contacts, ${ }^{16,17}$ and the 0.55 and $0.8 \mathrm{eV}$ electron traps (corresponding concentrations of $9.8 \times 10^{13}$ and $\left.3.1 \times 10^{14} \mathrm{~cm}^{-3}\right)$. The density of electron traps in the bulk of the film was orders of magnitude lower, the dominant centers being the $0.55 \mathrm{eV}$ (apparent concentra-

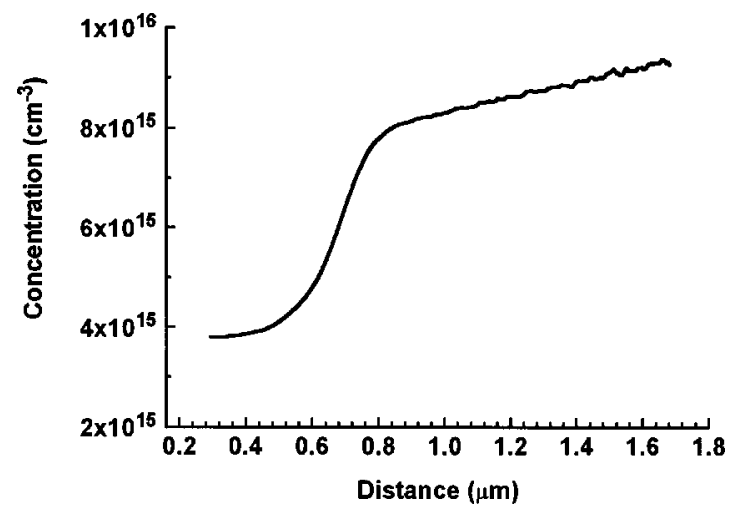

FIG. 2. Carrier concentration profile deduced from $1 \mathrm{MHz}, 290 \mathrm{~K} \mathrm{C}-V$ measurements from 0 to $-20 \mathrm{~V}$ on the $\mathrm{N}$ side of the sample. 
TABLE I. Characteristics of the shallow and deep centers in the freestanding Samsung sample on the Ga side and the $\mathrm{N}$ side. $N_{d 1}, N_{d 2}$ below are the shallow donor concentrations deduced from $C-V$ slopes in the damaged region and the bulk, $V_{\mathrm{bi}}$ is the intercept value correspondingly measured in the dark and after illumination and $15 \mathrm{~min}$ rest in the dark, $w_{0}$ is the space charge width at $0 \mathrm{~V}$ under illumination [see Eq. (1)], $N_{\text {deep }}$ is the density of deep hole traps calculated from Eq. (1), and $N_{\text {PPC }}$ is the density of persistent photocapacitance centers obtained as a difference between the dark values and the values measured from $C-V$ slopes after illumination and $15 \mathrm{~min}$ rest.

\begin{tabular}{|c|c|c|c|c|c|c|c|}
\hline Face & $\begin{array}{c}\text { Measurement } \\
\text { conditions at } \\
85 \mathrm{~K}\end{array}$ & $\begin{array}{l}N_{d 1} \\
10^{15} \\
\mathrm{~cm}^{-3}\end{array}$ & $V_{\mathrm{bi}}, \mathrm{V}$ & $\begin{array}{c}N_{d 2}, \\
10^{15} \\
\mathrm{~cm}^{-3}\end{array}$ & $\begin{array}{c}w_{0} \\
\text { Under } \\
\text { illumina- } \\
\text { tion, } \mu \mathrm{m}\end{array}$ & $\begin{array}{l}N_{\text {deep }}, \\
\mathrm{cm}^{-3}\end{array}$ & $\begin{array}{l}N_{\mathrm{PPC}}, \\
\mathrm{cm}^{-3}\end{array}$ \\
\hline \multirow{2}{*}{$\begin{array}{l}\mathrm{Ga} \\
\text { face }\end{array}$} & Dark & 3.01 & 0.693 & 5.57 & 0.39 & $8.8 \times 10^{14}$ & $3 \times 10^{13}$ \\
\hline & $\begin{array}{l}\text { After } \\
\text { illumination }\end{array}$ & 3.04 & 0.573 & 5.59 & & & \\
\hline \multirow{2}{*}{$\begin{array}{l}\mathrm{N} \\
\text { face }\end{array}$} & Dark & 3.96 & 0.521 & 7.60 & 0.31 & $1.3 \times 10^{15}$ & $5 \times 10^{13}$ \\
\hline & $\begin{array}{l}\text { After } \\
\text { illumination }\end{array}$ & 4.01 & 0.437 & 7.62 & & & \\
\hline
\end{tabular}

tion of $\left.2.1 \times 10^{13} \mathrm{~cm}^{-3}\right)$, the $0.65 \mathrm{eV}\left(1.4 \times 10^{13} \mathrm{~cm}^{-3}\right)$, and the $0.9 \mathrm{eV}$ traps. (With the time-window settings used in the figure only the beginning of the $0.9 \mathrm{eV}$ peak is seen but it can be clearly observed with longer time windows; the apparent concentration of the $0.9 \mathrm{eV}$ trap on the $\mathrm{Ga}$ side was 2.1 $\times 10^{13} \mathrm{~cm}^{-3}$ ).

These findings are in perfect agreement with an earlier report by some of the authors of this article on the existence of the RIE-induced surface damage region with higher density of deep traps compared to the bulk of the freestanding thick HVPE grown Samsung samples.

\section{B. Deep hole traps and persistent capacitance}

In our earlier articles ${ }^{8,13}$ we showed that illumination at low temperature of undoped $n$-GaN samples causes quite a measurable decrease in the intercept values of the $1 / C^{2}(V)$ characteristics due to charging of deep hole traps with levels located below the Fermi level. At low temperature the increase of capacitance and the decrease of the intercept values are metastable because no free electrons are readily available in the space charge region to be recaptured by the deep traps. Application of the forward bias supplying the necessary elec-

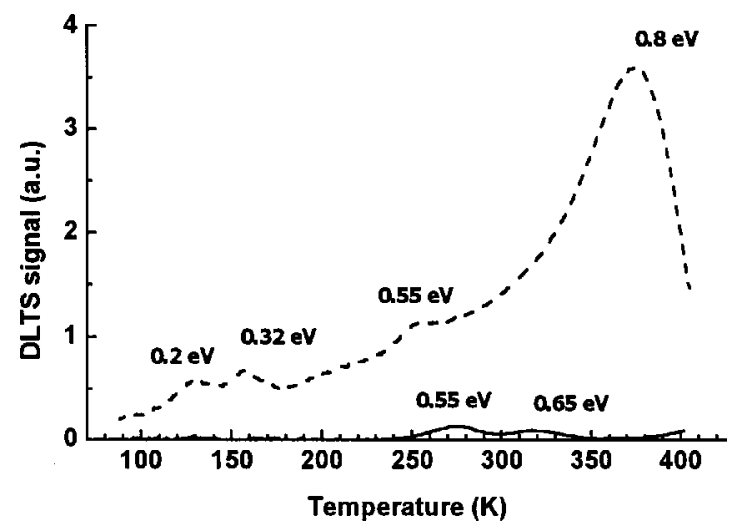

FIG. 3. The DLTS spectra taken on the Ga side of the sample near the surface (reverse bias $-0.8 \mathrm{~V}$, forward bias pulse of $1 \mathrm{~V}$ ) (dashed line) and in the bulk (reverse bias $-3 \mathrm{~V}$, forward bias $-1 \mathrm{~V}$ ) (solid line); other measurement conditions were as follows: sampling time windows $t_{1} / t_{2}$ $=100 \mathrm{~ms} / 1000 \mathrm{~ms}$, injection pulse length $2 \mathrm{~s}$. trons returns the intercept to its initial value. The density of the traps $\mathrm{N}_{\text {deep }}$ is related to the change in the intercept value $\Delta V_{\text {bi }}$ by the expression ${ }^{18}$

$$
\Delta V_{\mathrm{bi}}=q \cdot \mathrm{N}_{\text {deep }} \cdot w_{0}^{2} /\left(2 \epsilon \epsilon_{0}\right),
$$

where $w_{0}$ is the space charge region width under illumination (i.e., it is assumed that this is the thickness down to which the deep traps are recharged), $q$ is the electron charge, $\epsilon_{0}$ is the permittivity of vacuum, and $\epsilon$ is the relative permittivity. It was shown that the hole traps form a band of states and that the aggregate density of these states correlates with the dislocation density. ${ }^{8}$ In the freestanding sample studied in this article it would therefore be expected that the magnitude of the effect described by Eq. (1) would be considerably lower than that in the HVPE samples studied in Ref. 8, since the dislocation density is much lower in the present sample. As seen in Fig. 4, the effect of the change in the intercept value after illumination is indeed observed for the Samsung sample. The application of forward bias can return the intercept to its pre-illumination value as described previously for variously grown HVPE or metalorganic chemical vapor deposition-grown samples. ${ }^{8,13}$ The figure refers to the $\mathrm{Ga}$ face of the sample but the results were qualitatively similar

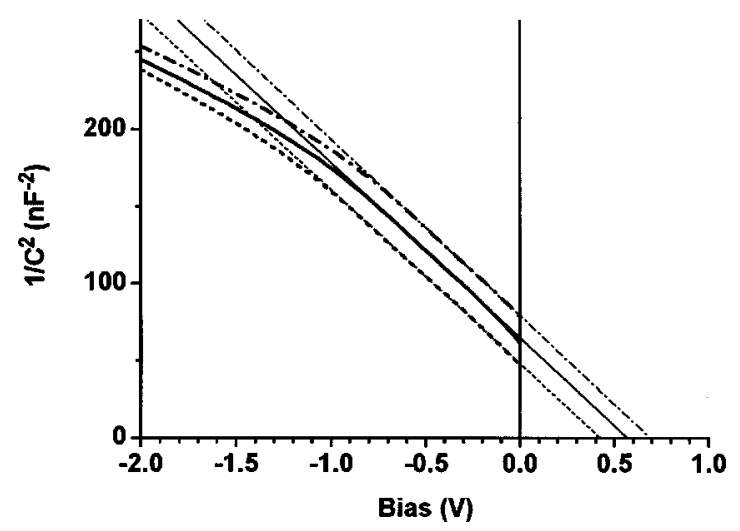

FIG. 4. $C-V$ characteristics $(85 \mathrm{~K}, 1 \mathrm{MHz})$ taken on the $\mathrm{Ga}$ side after cooling down in the dark (dashed line), under illumination with a deuterium lamp UV light source (dotted line), and $15 \mathrm{~min}$ after illumination (solid line). 


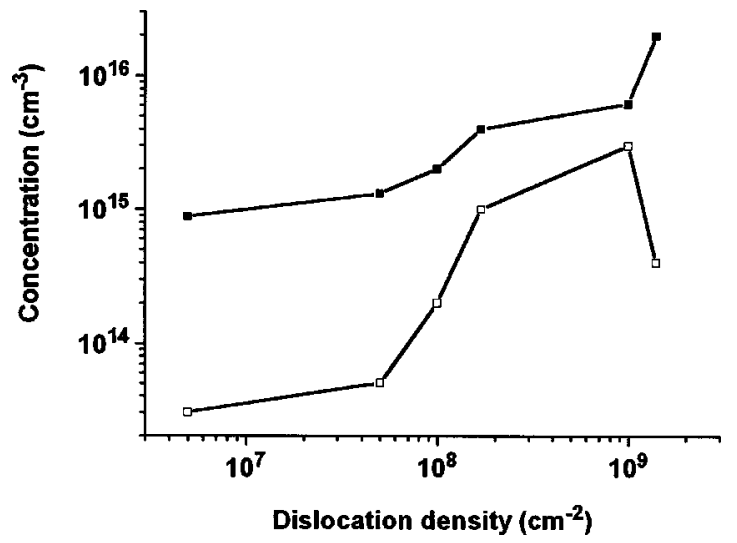

FIG. 5. The density of deep hole traps obtained from low-temperature $C-V$ measurements using Eq. (1) (closed squares) and the density of PPC-active centers (open squares) deduced from the difference in low-temperature concentrations obtained from $C-V$ slopes when cooling the sample in the dark and after illumination, both as a function of dislocation density; the set includes the HVPE $n$-GaN samples of different thicknesses studied in Ref. 8 (the thickness was converted into the dislocation density using TEM results of Ref. 20) and the Ga and the N sides of the freestanding Samsung sample studied in this article (a dislocation density of $5 \times 10^{6} \mathrm{~cm}^{-2}$ was attributed to the Ga side and $5 \times 10^{7} \mathrm{~cm}^{-2}$ to the $\mathrm{N}$ side based on earlier measurements on similarly grown samples ${ }^{4}$ ).

for the $\mathrm{N}$ face. The necessary data to calculate the densities of deep traps and the resultant concentrations are summarized in Table I. If we ascribe a dislocation density of about $5 \times 10^{6} \mathrm{~cm}^{-2}$ to the Ga face and about $5 \times 10^{7} \mathrm{~cm}^{-2}$ to the $\mathrm{N}$ face and plot the concentration of deep hole traps versus dislocation density together with the results obtained earlier in Ref. 8 for a set of HVPE samples with various thicknesses, we get the resultant curve in Fig. 5. It can be seen that, although the trend to decrease the density of the deep hole traps with decreasing dislocation density still holds, the curve definitely flattens out for low dislocation densities. Whether this is the result of the existence of a certain background of deep hole traps not directly related to dislocations or a consequence of the presence of the damaged region at the surface where the density of deep hole traps is enhanced remains to be seen by measuring the samples with the damaged region removed, e.g., by photoelectrochemical etching (such experiments are being planned in the near future).

Another feature following from capacitance-voltage measurements on the freestanding Samsung sample at low temperature is the very low density of true-persistentphotocapacitance-active centers in this sample. The standard way to determine the presence of such centers and to determine their concentration is to cool the sample at $0 \mathrm{~V}$ in the dark, measure the $C-V$ characteristic, then shine light on the sample and again measure the $C-V$ characteristic (see, e.g., a discussion and relevant references in Refs. 8, 9, and 13). If certain centers with a barrier for capture of electrons are present, the apparent electron concentration after illumination will be higher than the dark value by the density of these persistent photocapacitance centers (see, e.g., Ref. 9). Note that the nature of this effect is totally different from that described above in relation to that described in Eq. (1): recharging of the deep hole traps with levels below the Fermi level changes the capacitance and the intercept value but not the apparent electron concentration. ${ }^{8}$ As can be seen from Table I, the concentration of PPC-active centers calculated as the difference between the electron concentration in the dark and after illumination is only $5 \times 10^{13} \mathrm{~cm}^{-3}$ at the surface of the sample at the $\mathrm{N}$ face and $3 \times 10^{13} \mathrm{~cm}^{-3}$ at the Ga face (respective concentrations in the bulk are about 2 $\times 10^{13} \mathrm{~cm}^{-3}$ ). The nature of the centers is not completely understood at the moment. In Ref. 13 we ascribed at least part of the effect to the presence of deep electron traps with 0.55 and $0.8 \mathrm{eV}$ having appreciable barriers for capture of electrons (see also Ref. 19). It was again instructive to compare the values obtained on the Samsung sample with those measured on the set of HVPE $n$-GaN films with different thicknesses and different dislocation densities studied in detail in Ref. 8. Measurements of concentration of the PPC centers were made in the same way as described above. The accuracy for the thicker samples was not great because of the carrier concentrations being close to $10^{17} \mathrm{~cm}^{-3}$. The thicknesses were converted to dislocation density using the TEM results published in Ref. 20. Graphically the data are presented as a function of dislocation density in Fig. 5. At high dislocation densities the density of PPC centers is also quite high and seems to be related to the change in the density of the $0.55 \mathrm{eV}$ electron traps (see Ref. 20) although the relation is not one to one. This possibly explains the low density of PPC centers observed at the highest dislocation densities because at this point the $0.55 \mathrm{eV}$ traps were switched for the $0.65 \mathrm{eV}$ traps. ${ }^{20}$ At lower dislocation densities the PPC concentration steadily decreases. The full explanation of the effect is lacking at the moment. It could be pointed out that the density of all electron traps including those that are suspected as PPC-active centers also steadily decreases with decreased dislocation density. But part of the effect could also be due to the presence of certain deep centers in the vicinity of dislocations where they are surrounded by a potential barrier and thus should be PPC active. More work needs to be performed on this important subject, but, whatever the exact model, it is obvious that reducing the dislocation density has a beneficial effect on decreasing the number of PPC-active centers that are very undesirable in modulation doped transistors, photodetectors, and many other applications.

\section{DLTS studies}

It is instructive to compare the DLTS spectra with electrical pulse excitation (electron traps) and optical pulse excitation (hole traps) for the bulk of the Samsung freestanding sample on the $\mathrm{Ga}$ and the $\mathrm{N}$ side. In Fig. 6 we compare the electron trap spectra. The high-energy peak could not be properly measured with the time window settings used in Figs. 6 and in Fig. 7 where we compare the spectra with longer sampling times. The results of the measurements are summarized in Table II. It can be seen that the overall concentration of traps is very low; the densities of all traps but those at $0.9 \mathrm{eV}$ are slightly higher on the $\mathrm{N}$ side. Moreover, when the measurements were performed on the $\mathrm{N}$ side with bias voltage and pulse voltage settings of $-3 \mathrm{~V} /-1 \mathrm{~V}$ (dashed curve in Fig. 6) and $-10 \mathrm{~V} /-3 \mathrm{~V}$ (dash-dotted curve in Fig. 6) it could be seen that the densities of the traps were 


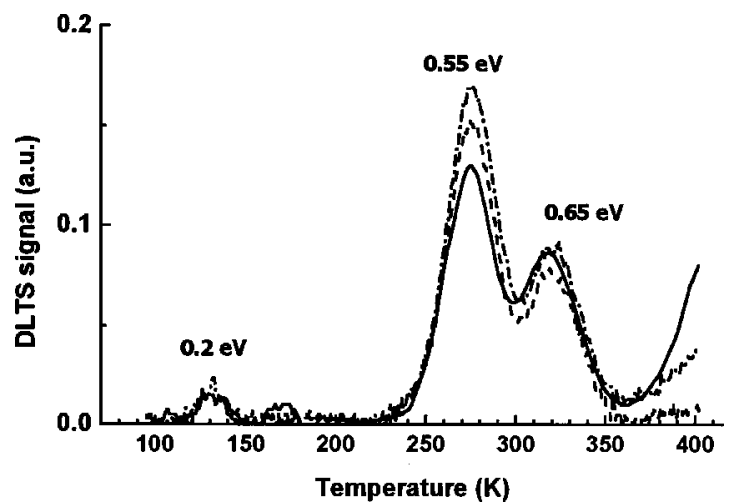

FIG. 6. Comparison of the bulk electron trap spectra taken on the Ga side (solid curve) and the $\mathrm{N}$ side (dash-dotted curve); measurement conditions: reverse voltage of $-3 \mathrm{~V}$, forward bias pulse of $-1 \mathrm{~V}$ ( $2 \mathrm{~s}$ long), $t_{1} / t_{2}$ $=100 \mathrm{~ms} / 1000 \mathrm{~ms}$; also shown is the spectrum taken on the $\mathrm{N}$ side with even higher reverse voltage of $-10 \mathrm{~V}$, with a forward bias pulse of $-3 \mathrm{~V}(2$ s long; other conditions the same as for the other two curves) (dashed curve).

slightly decreasing when going deeper into the bulk. Thus it is unexpected that the $0.9 \mathrm{eV}$ trap does not follow the trend and a plausible explanation of that is lacking at the moment. The above findings are generally in tune with the earlier report on the dependence of the deep level spectra in HVPE $n$-GaN on the layer thickness and hence the dislocation density. Optical DLTS results are presented in Fig. 8. Earlier we reported that in HVPE $n$-GaN samples the main features are the broad structureless band of states and the deep hole traps with activation energy close to $0.9 \mathrm{eV}{ }^{8}$ The density of the $E_{v}+0.9 \mathrm{eV}$ traps tended to decrease with decreased dislocation density. It can be seen in Fig. 8 (the densities of the traps are presented in Table II) that this tendency seems to be preserved for the spectra taken on the Ga side (lower dislocation density) and the $\mathrm{N}$ side (higher dislocation density). It should also be mentioned that the density of these hole traps is substantially lower than that of the HVPE samples with dislocation densities in the $10^{9}-10^{8} \mathrm{~cm}^{-2}$ range. $^{8}$

\section{EBIC measurements}

In Figs. 9(a) and 9(b) we compare the EBIC images obtained for the Ga side [Fig. 9(a)] and the $\mathrm{N}$ side [Fig.

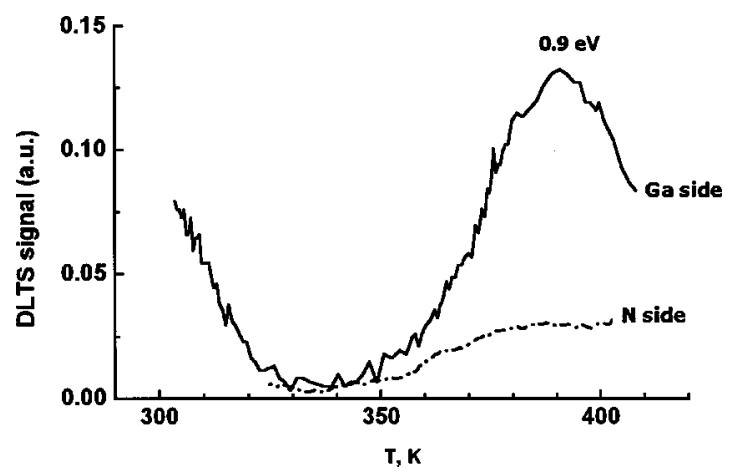

FIG. 7. Bulk DLTS spectra taken on the Ga side (solid line) and the $\mathrm{N}$ side (dashed line) showing more clearly the $0.9 \mathrm{eV}$ electron trap related peak; measurement conditions: reverse bias of $-3 \mathrm{~V}$, forward bias pulse of $-1 \mathrm{~V}$ ( $2 \mathrm{~s}$ long), $t_{1} / t_{2}=1 \mathrm{~s} / 10 \mathrm{~s}$.

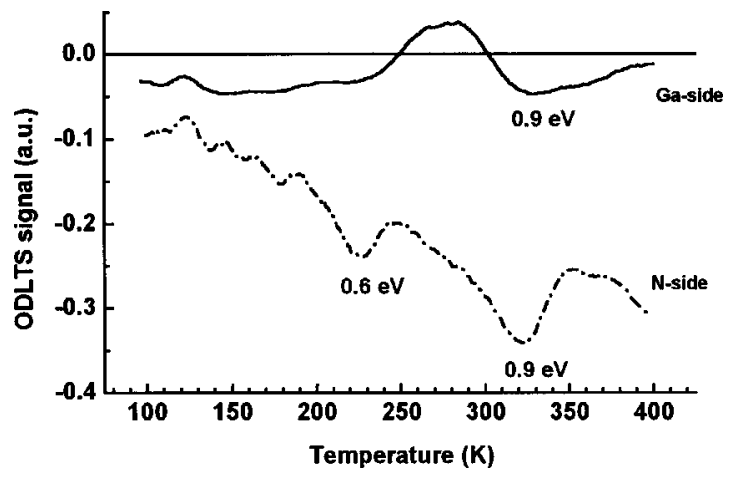

FIG. 8. Optical DLTS spectra taken on the Ga side (solid line) and the N side (dash-dotted line); measurement conditions: reverse bias $-2 \mathrm{~V}$, optical injection pulse by the $D_{2}$ lamp UV light source ( $2 \mathrm{~s}$ long), $t_{1} / t_{2}$ $=100 \mathrm{~ms} / 1000 \mathrm{~ms}$.

9(b)]. The main features in both figures are the dark dot defects related to the enhanced density of recombination centers. Very interestingly, the density of such defects on the $\mathrm{Ga}$ side is considerably lower than on the $\mathrm{N}$ side and the overall surface concentration of the dark dot defects is close to the expected density of dislocations. This suggests that the dislocations in $n$-GaN are efficient recombination centers, which agrees well with the results of measurements of the dependence of the diffusion length of holes on dislocations density in HVPE samples of various thicknesses. ${ }^{21}$ Measurements of diffusion length on the $\mathrm{Ga}$ and $\mathrm{N}$ sides of our sample are also in tune with these observations. The diffusion length on the $\mathrm{Ga}$ side was $0.9-1.2 \mu \mathrm{m}$ for different diodes, whereas on the $\mathrm{N}$ side it was slightly lower, $0.7-0.9$ $\mu \mathrm{m}$. However, at least in the case of the Ga side, the dislocation density is too low for the space charge regions of the low-angle walls to overlap [in fact, from Fig. 9(a) it is seen that the dislocations, if the dark spots in the figure are the dislocations, no longer form cellular structure but rather are more or less randomly distributed]. Hence the general assumptions of the model successfully describing the diffusion length in mosaic GaN films with higher dislocation density ${ }^{21}$ might not be valid and the diffusion length in this case seems to be determined by the recombination in the bulk of the film and not on grain boundaries, although the impact of recom-

TABLE II. Deep level characteristics obtained for the bulk portions of the freestanding Samsung sample on the Ga side and the $\mathrm{N}$ side.

\begin{tabular}{cllc}
\hline \hline \multirow{2}{*}{ Sample side } & Trap type & $\begin{array}{c}\text { Activation energy, } \\
\mathrm{eV}\end{array}$ & $\begin{array}{c}\text { Concentration, } \\
\mathrm{cm}^{-3}\end{array}$ \\
\hline \multirow{2}{*}{$\mathrm{Ga}$} & Electron & 0.2 & $3.3 \times 10^{12}$ \\
& Electron & 0.55 & $2.1 \times 10^{13}$ \\
& Electron & 0.65 & $1.4 \times 10^{13}$ \\
& Electron & 0.9 & $2.1 \times 10^{13}$ \\
& Hole & 0.9 & $8.1 \times 10^{12}$ \\
\hline \multirow{2}{*}{$\mathrm{N}$} & Electron & 0.2 & $3.8 \times 10^{12}$ \\
& Electron & 0.55 & $3.8 \times 10^{13}$ \\
& Electron & 0.65 & $2 \times 10^{13}$ \\
& Electron & 0.9 & $6.6 \times 10^{12}$ \\
& Hole & 0.6 & $5.3 \times 10^{13}$ \\
& Hole & 0.9 & $7.5 \times 10^{13}$ \\
\hline \hline
\end{tabular}




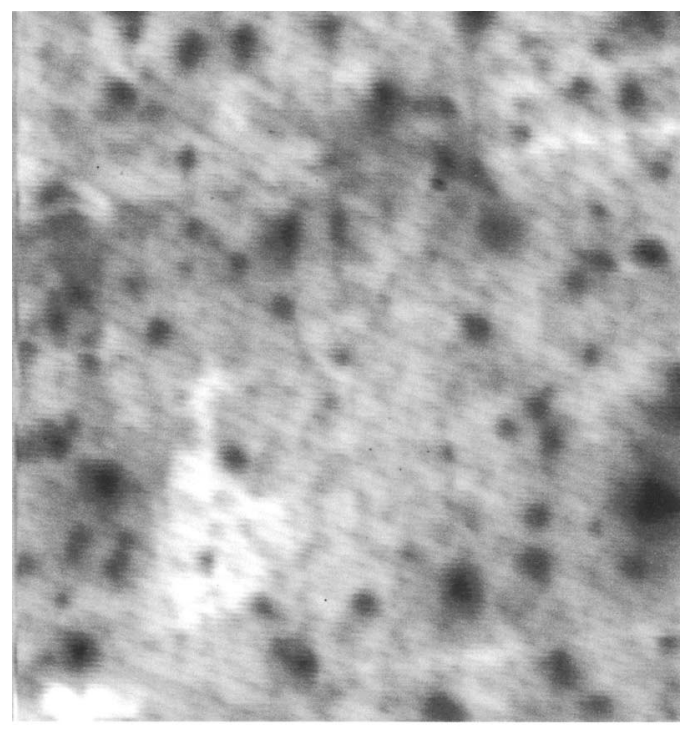

(a)

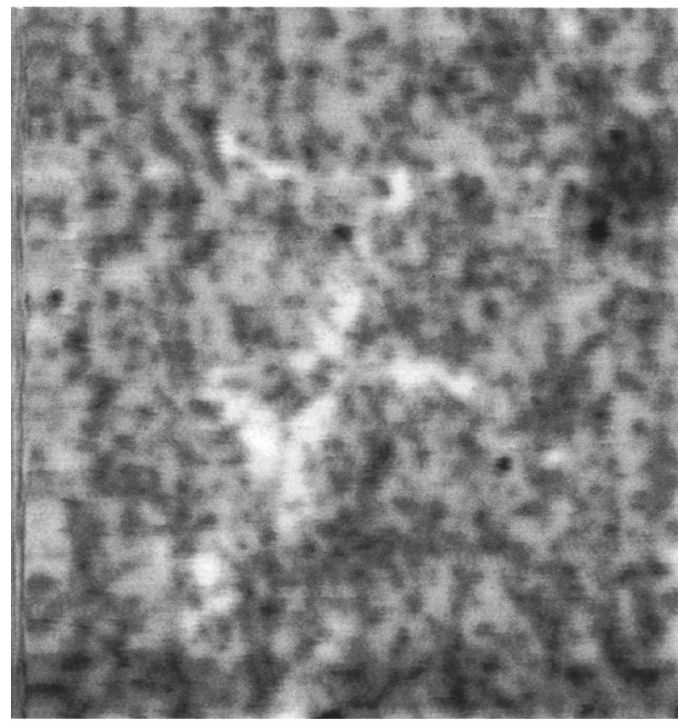

(b)

FIG. 9. (a) EBIC image of a portion of the Schottky diode prepared on the Ga side; (b) the same for the N side; observation conditions the same in both cases: accelerating voltage $25 \mathrm{kV}$, zero bias, $\times 1000$, the full scale of the figure is $120 \mu \mathrm{m} \times 120 \mu \mathrm{m}$.

bination in the damaged surface region has yet to be estimated. The diffusion length measured on the $\mathrm{N}$ side is again lower than the characteristic dimensions of the domains separated by low-angle boundaries as judged from the EBIC image in Fig. 9(b) so that the bulk recombination could be also dominant in that case.

\section{E. $I-V$ characteristics}

In Fig. 10 we compare the reverse $I-V$ characteristics of the Schottky diodes prepared on the Ga side and on the N side (the forward current portions did not differ much showing similar ideality factors of 1.01-1.03 and very low series resistance because of the excellent electrical properties of the film). The reverse current was substantially higher for the $\mathrm{N}$ side indicating once again the importance of dislocations in

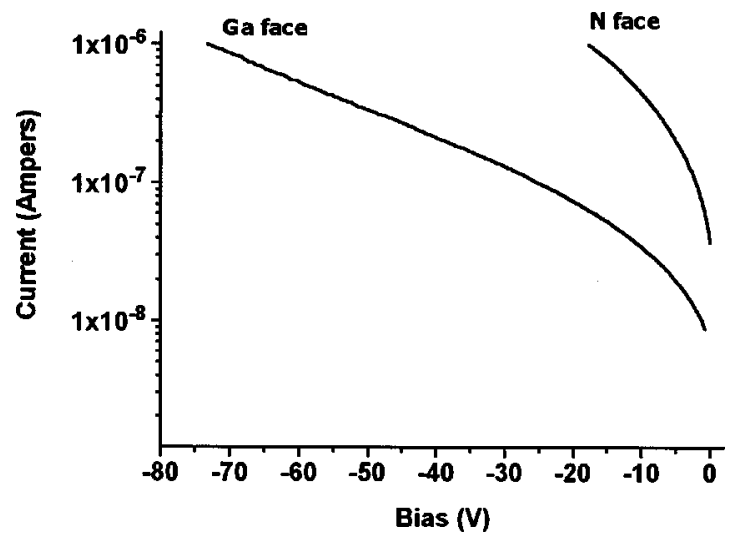

FIG. 10. Reverse current at $290 \mathrm{~K}$ measured on the Schottky diodes prepared on the Ga side and the $\mathrm{N}$ side of the sample; the reverse current in these measurements was somewhat arbitrarily limited by a value of $1 \mu \mathrm{A}$.

the current transport in $n$-GaN Schottky diodes. Note that the diode structure was in no way optimized, i.e., the ohmic contact was made on the same side as the Schottky diode (so that leakage through the damaged surface region was a factor), no attempt at sensible Schottky barrier edge termination by applying guard rings, etc., was made and the diode area was quite large. Even so, the reverse current on the Ga side was only $1 \mu \mathrm{A}$ at $70 \mathrm{~V}$ and nowhere close to breakdown, so that it might be said that the material shows great promise for Schottky diode rectifiers, once all the necessary precautions are taken.

\section{CONCLUSIONS}

We have shown that at the top of the freestanding $n$-GaN sample grown at Samsung there exists, both on the Ga side and on the $\mathrm{N}$ side, a damaged surface layer about $0.5 \mu \mathrm{m}$ thick that is characterized by a strongly reduced electron concentration and a strongly enhanced density of deep traps compared to the bulk of the film. This layer comes most probably from the RIE process used to improve the surface morphology of the sample, and, unfortunately, has a serious impact on some of the measurements reported herein. Nevertheless, the bulk concentrations of deep electron and hole traps in the freestanding Samsung sample are among the lowest ever measured in undoped $n$-GaN. The density of these bulk traps is quite measurably lower for the Ga side with lower dislocation density compared to the $\mathrm{N}$ side with higher dislocation density. The only exception is the $0.9 \mathrm{eV}$ electron trap whose concentration, quite unexpectedly, is higher on the Ga side, probably because the traps in question are simple point defects not related to dislocations, although some previous reports to the contrary have been published. This question needs further study.

The density of deep hole traps measured either from low-temperature $C-V$ characteristics or from optical DLTS, again, are considerably lower than reported previously for the higher dislocation density HVPE samples ${ }^{8}$ and the concentration of the hole traps seems to be measurably higher on the $\mathrm{N}$ side which supports the existence of the trend observed earlier on the set of HVPE samples with varying thickness and varying dislocation density. However, the amount of de- 
crease with dislocation density in the Samsung sample is not as strong as could be anticipated, possibly because of the impact of the deep holes in the damaged layer (it is very difficult to avoid their influence with optical excitation). It has also been noticed that the density of deep centers with a barrier for capture of electrons, i.e., true PPC centers, is very low in the Samsung sample compared to the previously measured HVPE samples with a higher dislocation density. EBIC results reveal the presence in the Samsung sample of the dark-spot defects and interestingly the density of the dark spots on the Ga side is much lower than that on the $\mathrm{N}$ side and both correlate with expected dislocation densities at corresponding surfaces.

Finally, it has been shown that the reverse current measured on the $\mathrm{N}$ side is very much higher than on the Ga side which supports the idea that suppressing the dislocation density in $n$-GaN has a beneficial effect on reverse current, in our case, even for dislocation densities as low as $5 \times 10^{6}-5$ $\times 10^{7} \mathrm{~cm}^{-2}$.

All in all the presented results demonstrate a very high quality of the Samsung material and suggest that it could prove to be of much use in many applications.

\section{ACKNOWLEDGMENTS}

The work at IRM was supported in part by the Russian Foundation for Basic Research (RFBR Grant No. 01-0217230). D.C.L. and Z.Q.F. were supported under AFOSR Grant No. F49620-00-1-0347. The authors would like to thank E. F. Astakhova for the Schottky diodes preparation.

${ }^{1}$ S. S. Park, Il.-W. Park, and S. H. Choh, Jpn. J. Appl. Phys., Part 2 39, L1141 (2000).

${ }^{2}$ F. Yun, M. A. Reshchikov, K. M. Jones, P. Visconti, H. Morkoç, S. S. Park, and K. Y. Lee, Solid-State Electron. 44, 2225 (2000).
${ }^{3}$ J. A. Freitas, Jr., G. C. B. Braga, W. J. Moore, J. G. Tischler, J. C. Culbertson, M. Fatemi, S. S. Park, S. K. Lee, and Y. Park, J. Cryst. Growth 231, 322 (2001).

${ }^{4}$ J. Jasinski, W. Swider, Z. Litiental-Weber, P. Visconti, K. M. Jones, M. A. Reshchikov, F. Yun, H. Morkoç, S. S. Park, and K. Y. Lee, Appl. Phys. Lett. 68, 2297 (2001).

${ }^{5}$ D. C. Look and J. R. Sizelove, Appl. Phys. Lett. 79, 1133 (2001).

${ }^{6}$ Z.-Q. Fang, D. C. Look, P. Visconti, D.-F. Wang, C.-Z. Lu, F. Yun, H. Morkoç, S. S. Park, and K. Y. Lee, Appl. Phys. Lett. 78, 2178 (2001).

${ }^{7}$ M. A. Reshchikov, H. Morkoç, S. S. Park, and K. Y. Lee, Appl. Phys. Lett. 78, 3041 (2001)

${ }^{8}$ A. Y. Polyakov, N. B. Smirnov, A. V. Govorkov, Z.-Q. Fang, D. C. Look, R. J. Molnar, and A. V. Osinsky, J. Appl. Phys. 91, 6580 (2002).

${ }^{9}$ P. M. Mooney, J. Appl. Phys. 67, R1 (1990).

${ }^{10}$ A. Y. Polyakov, N. B. Smirnov, A. V. Govorkov, D. W. Greve, M. Skowronski, M. Shin, and J. M. Redwing, MRS Internet J. Nitride Semicond. Res. 3, 37 (1998).

${ }^{11}$ D. V. Lang, J. Appl. Phys. 45, 3023 (1974).

${ }^{12}$ G. M. Martin, A. Mittoneau, D. Pons, A. Mircea, and D. W. Woodard, J. Phys. C 13, 3855 (1980).

${ }^{13}$ A. Y. Polyakov, N. B. Smirnov, A. V. Govorkov, M. G. Mil'vidskii, A. S. Usikov, N. M. Shmidt, B. V. Pushnyi, D. V. Tsvetkov, S. I. Stepanov, and V. A. Dmitriev, MRS Internet J. Nitride Semicond. Res. 5S1, W11.81 (2000).

${ }^{14}$ A. Y. Polyakov, A. V. Govorkov, N. B. Smirnov, M. G. Mil'vidskii, J. M. Redwing, M. Shin, M. Skowronski, and D. W. Greve, Solid-State Electron. 42, 637 (1998).

${ }^{15}$ A. Y. Polyakov, N. B. Smirnov, A. V. Govorkov, M. Shin, M. Skowronski, and D. W. Greve, J. Appl. Phys. 84, 870 (1998).

${ }^{16}$ Z.-Q. Fang, J. W. Hemsky, D. C. Look, and M. P. Mack, Appl. Phys. Lett. 72, 448 (1998).

${ }^{17}$ F. D. Auret, S. A. Goodman, F. K. Koschnick, J.-M. Spaeth, B. Beaumont, and P. Gibart, Appl. Phys. Lett. 74, 2173 (1999).

${ }^{18}$ L. S. Berman and A. A. Lebedev, Capacitance Spectroscopy of Deep Centers in Semiconductors (Nauka, Leningrad, 1981) (in Russian).

${ }^{19}$ A. Y. Polyakov, N. B. Smirnov, A. S. Usikov, A. V. Govorkov, and B. V. Pushniy, Solid-State Electron. 42, 1959 (1998).

${ }^{20}$ Z.-Q. Fang, D. C. Look, J. Jasinski, M. Benamara, Z. Liliental-Weber, and R. J. Molnar, Appl. Phys. Lett. 78, 332 (2001).

${ }^{21}$ L. Chernyak, A. Osinsky, G. Nootz, A. Schulye, J. Jasinski, M. Benamara, Z. Liliental-Weber, D. C. Look, and R. J. Molnar, Appl. Phys. Lett. 77, 2695 (2000). 